\title{
Peptide-modified liposomes for selective targeting of bombesin receptors overexpressed by cancer cells: a potential theranostic agent
}

This article was published in the following Dove Press journal:

International Journal of Nanomedicine

16 April 2012

Number of times this article has been viewed

\author{
Antonella Accardo ${ }^{1,2 *}$ \\ Giuseppina Salsano ${ }^{3 *}$ \\ Anna Morisco ${ }^{4}$ \\ Michela Aurilio ${ }^{4}$ \\ Antonio Parisi ${ }^{5}$ \\ Francesco Maione ${ }^{5}$ \\ Carla Cicala ${ }^{5}$ \\ Diego Tesauro ${ }^{1,2}$ \\ Luigi Aloj ${ }^{4}$ \\ Giuseppe De Rosa ${ }^{3}$ \\ Giancarlo Morelli,
}

'CIRPeB, Department of Biological Sciences and IBB CNR, University of Naples "Federico II", Invectors srl, ${ }^{3}$ Department of Pharmaceutical Chemistry, University of Naples "Federico II", ${ }^{4}$ Department of Nuclear Medicine, Istituto Nazionale per lo Studio e la Cura dei Tumori, Fondazione "G. Pascale", ${ }^{5}$ Department of Experimental Pharmacology, University of Naples "Federico II", Napoli, Italy

*These authors contributed equally to this work

\begin{abstract}
Objectives: Drug delivery systems consisting of liposomes displaying a cell surface receptor-targeting peptide are being developed to specifically deliver chemotherapeutic drugs to tumors overexpressing a target receptor. This study addresses novel liposome composition approaches to specifically target tissues overexpressing bombesin (BN) receptors.
\end{abstract}

Methods: A new amphiphilic peptide derivative (Mon Y-BN) containing the BN(7-14) peptide, the DTPA (diethylenetriaminepentaacetate) chelating agent, a hydrophobic moiety with two $\mathrm{C}_{18}$ alkyl chains, and polyethylene glycol spacers, has been synthesized by solid-phase methods. Liposomes have been generated by co-aggregation of Mon Y-BN with 1,2-distearoyl-sn-glycero3-phosphocholine (DSPC). The structural and biological properties of these new target-selective drug-delivery systems have been characterized.

Results: Liposomes with a DSPC/MonY-BN (97/3 molar ratio) composition showed a diameter of $145.5 \pm 31.5 \mathrm{~nm}$ and a polydispersity index of $0.20 \pm 0.05$. High doxorubicin (Dox) loading was obtained with the remote $\mathrm{pH}$ gradient method using citrate as the inner buffer. Specific binding to PC-3 cells of DSPC/Mon Y-BN liposomes was obtained $\left(2.7 \% \pm 0.3 \%\right.$, at $\left.37^{\circ} \mathrm{C}\right)$, compared with peptide-free DSPC liposomes $\left(1.4 \% \pm 0.2 \%\right.$ at $\left.37^{\circ} \mathrm{C}\right)$. Incubation of cells with DSPC/ MonY-BN/Dox showed significantly lower cell survival compared with DSPC/Dox-treated cells, in the presence of $100 \mathrm{ng} / \mathrm{mL}$ and $300 \mathrm{ng} / \mathrm{mL}$ drug amounts, in cytotoxicity experiments. Intravenous treatment of PC-3 xenograft-bearing mice with DSPC/MonY-BN/Dox at $10 \mathrm{mg} / \mathrm{kg}$ Dox dose produced higher tumour growth inhibition (60\%) compared with nonspecific DSPC/ Dox liposomes (36\%) relative to control animals.

Conclusion: The structural and loading properties of DSPC/MonY-BN liposomes along with the observed in-vitro and in-vivo activity are encouraging for further development of this approach for target-specific cancer chemotherapy.

Keywords: bombesin peptide, doxorubicin delivery, gastrin-releasing peptide receptors, PC-3 cells, theranostic applications

\section{Introduction}

Conventional doxorubicin (Dox) is an established cytotoxic agent for many cancer types (in particular, breast and ovarian cancer), and its use has been shown to be clinically effective. However, irreversible cardiac toxicity has been one of the primary dose-limiting factors in the use of this $\mathrm{drug}^{1}$ and, consequently, many research efforts have been directed towards improving its safety profile. A successful strategy for reducing the cardiac toxicity associated with conventional Dox involves encapsulation into liposomes, which alters the tissue distribution and pharmacokinetics of this drug while maintaining efficacy and improving the therapeutic index..$^{2,3}$ Liposomal Dox formulations (eg, Myocet ${ }^{\circledR}$ and Caelyx ${ }^{\circledR} /$ Doxil $^{\circledR}$ ) have shown reduced cardiac toxicity
Correspondence: Giancarlo Morelli CIRPeB, Department of Biological Sciences and IBB CNR, University of Naples "Federico II", Via Mezzocannone 16, 80 I 34 Napoli, Italy Tel +390812536650

Email gmorelli@unina.it 
compared with free Dox ${ }^{4-6}$ while preserving antitumor efficacy. The prolonged circulation times obtainable with this strategy, in particular for pegylated (Stealth) liposomes, allows preferential accumulation in tumor tissues given their leaky vasculature and poorly operating lymphatic system (enhanced permeability and retention effect). ${ }^{7-10}$

All liposomal drugs presently marketed, as well as others now in development, are based on "nonspecific" liposomes. The development of new nanovectors able to selectively deliver a chemo-therapeutic agent to cancer cells, may lead to increased therapeutic efficacy of the encapsulated drug, as well as reduce toxic side effects on nontarget cells. ${ }^{11}$ Peptides and antibodies have been largely investigated as bioactive markers used to confer selectivity to liposomes to target cells. ${ }^{12-14}$ It is well known that regulatory peptides, and fragments thereof, bind with high affinity to specific cell-surface receptors. Receptor systems such as the somatostatin (SSTR1-SSTR5) receptors, ${ }^{15}$ the vasoactive intestinal peptide receptor, ${ }^{16}$ cholecystokinin $2 /$ gastrin $\left(\mathrm{CCK}_{2}\right)$ receptors, ${ }^{17}$ gastrin-releasing peptide (GRP)/ bombesin (BN) receptors, ${ }^{18}$ and several others, ${ }^{19}$ are known to be overexpressed in specific human cancer types.

The authors of this present study have previously studied nanosized delivery systems, such as micelles and liposomes, modified with bioactive peptides on their external surface; these have been obtained by combining two different amphiphilic monomers, one containing a bioactive peptide (CCK8, Octreotide, or BN[7-14]) and the other containing a chelating agent (DTPAGlu, DTPA, or DOTA). Moreover, the authors also studied liposomes prepared by co-aggregation of a synthetic amphiphilic monomer containing both the bioactive peptide and the chelating agent, with commercial phospholipids. In both cases, targeted nanocarriers engineered to conjugate imaging and therapeutic functions ${ }^{20-24}$ were obtained for potential theranostic applications. Derivatized nanosystems, capable of diagnosis, drug delivery, and monitoring of therapeutic response, are expected to play a significant role in the dawning era of personalized medicine. ${ }^{25,26}$

Interesting results have been obtained by using the $\mathrm{BN}$ peptide. $^{27}$ The 14-residue $\mathrm{BN}$ peptide, its eight-residue C-terminal peptide sequence (BN[7-14]), or other BN analogues acting as antagonists may be used to target $\mathrm{BN}$ receptor subtype 2, also known as gastrin releasing peptide receptor (GRPR). GRP receptors have been found overexpressed in cell lines derived from several human tumor types (ovarian cancer, breast cancer, and prostate cancer). ${ }^{28-30}$ Many studies demonstrate that the $\mathrm{BN}(7-14)$ fragment modified on its N-terminus with radiometal complexes, for diagnostic or therapeutic nuclear medicine applications, preserves its affinity for these receptors. ${ }^{31-33}$ In-vitro and in-vivo experiments, carried out on radiolabeled liposomes containing the $\mathrm{BN}(7-14)$ peptide fragment, demonstrate that the peptide, exposed on the liposome surface, maintains the capability to selectively target aggregates to GRPR-expressing xenografts. ${ }^{27}$

This paper describes new BN-conjugated nanosystems for theranostic purposes with improved properties, both in the synthesis and formulation aspects and for their in-vitro and in-vivo behavior. These liposomes are based on the coaggregation of 1,2-distearoyl-sn-glycero-3-phosphocholine (DSPC) phospholipid with a new synthetic amphiphilic monomer, Mon Y-BN (Figure 1), containing in the same molecules the $\mathrm{BN}(7-14)$ peptide fragment, the DTPA chelating agent, the hydrophobic moiety with two C18 alkyl chains, and polyethylene glycol (PEG) spacers.

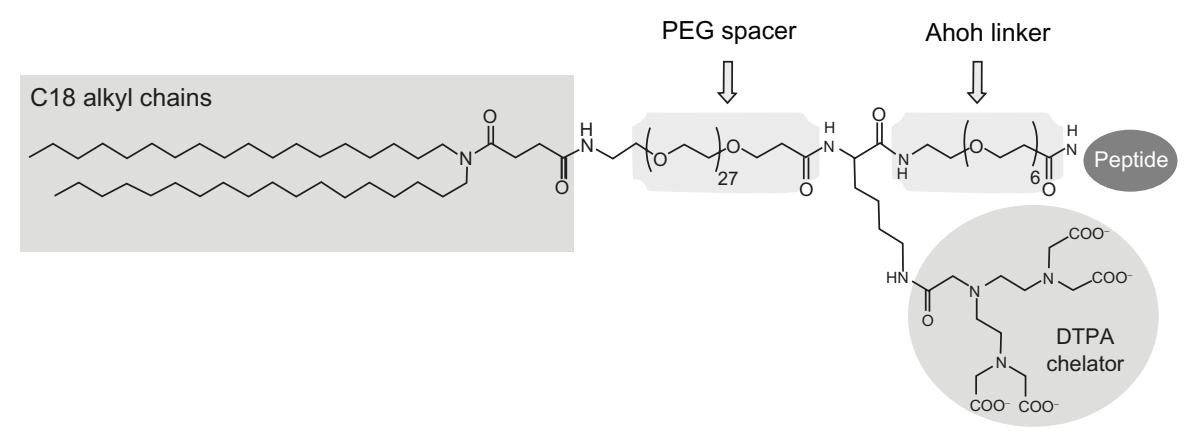

\section{Peptide sequence: GIn-Trp-Ala-Val-Gly-His-Leu-Met-Amide}

Figure I Schematic representation of MonY-Peg27(DTPA)-BN (MonY-BN).

Notes: MonY-BN molecule contains five components: a hydrophobic moiety with two $\mathrm{C}_{18}$ alkyl chains, a long polyoxoethilene spacer (Peg27), the DTPA chelating agent, a short linker (Ahoh), and the BN(7-14) peptide. The peptide sequence is reported using the three-letter amino acid code.

Abbreviations: BN, bombesin; DTPA, diethylenetriaminepentaacetate; PEG, polyethylene glycol. 


\section{Materials and methods}

\section{Instrumentation}

Preparative high-performance liquid chromatography (HPLC) was carried out on an LC8 Shimadzu HPLC system (Shimadzu Corporation, Kyoto, Japan) equipped with a UV lambda-Max Model 481 detector using a Phenomenex (Torrance) C4 (300 A, $250 \mathrm{~mm} \times 21.20 \mathrm{~mm}, 5 \mu)$ column eluted with an $\mathrm{H}_{2} \mathrm{O} / 0.1 \%$ trifluoroacetic acid (TFA) and $\mathrm{CH}_{3} \mathrm{CN} / 0.1 \%$ TFA from $20 \%$ to $95 \%$ over 25 minutes at $20 \mathrm{~mL} / \mathrm{min}$ flow rate. Liquid chromatography coupled to mass spectrometry (LC-MS) analyses were performed by using Finnigan Surveyor MSQ single quadrupole electrospray ionization (Finnigan/Thermo Electron Corporation, San Jose, CA). Ultraviolet (UV) measurements were performed on a UV-vis Jasco V-5505spectrophotometer equipped with a Jasco ETC-505T Peltier temperature controller with a 1-cm quartz cuvette (Hellma, Müllheim, Germany).

\section{Pharmaceuticals and reagents}

Protected N $\alpha$-Fmoc-amino acid derivatives, coupling reagents, and Rink amide MBHA resin were purchased from Calbio-chem-Novabiochem (Laufelfingen, Switzerland). The Fmoc-21-amino-4,7,10,13,16,19-hexaoxaheneicosanoic acid (Fmoc-Ahoh-OH) was purchased from Neosystem (Strasbourg, France). N,N-dioctadecylsuccinamic acid was prepared according to the experimental procedure reported in the literature. ${ }^{34} \alpha$-(9-Fluorenylmethyloxycarbonyl) amino- $\omega$-carboxy PEG (Fmoc-NH-Peg27-COOH) was purchased from Iris Biotech $\mathrm{GmbH}$ (Marktredwitz, Germany). $\mathrm{DTPA}(\mathrm{OtBu})_{4}-\mathrm{OH}$ (diethylenetriaminepentaacetate tetra-tertbutyl ester) was purchased from Macrocyclics (Dallas, TX). Citrate acid, sodium citrate, sodium chloride, and Dox were obtained from Sigma Chemical Co (St Louis, MO). All other chemicals were commercially available from Sigma-Aldrich, Fluka (Bucks, Switzerland) or LabScan (Stillorgan, Dublin, Ireland) and were used as received unless otherwise stated. 1,2distearoyl-sn-glycero-3-phosphocholine (DSPC) was purchased from Lipoid $\mathrm{GmbH}$ (Cam, Switzerland). All solutions were prepared by weight using doubly distilled water.

\section{Peptide synthesis}

Synthesis of $\left(\mathrm{C}_{18} \mathrm{H}_{37}\right)_{2} \mathrm{NCO}\left(\mathrm{CH}_{2}\right)_{2} \mathrm{CO}-\mathrm{Peg} 27-$ Lys(DTPA)-Ahoh-Gln-Trp-Ala-Val-Gly-His-Leu-MetAmide (MonY-BN)

Synthesis of MonY-BN was carried out in solid-phase under standard Fmoc strategy, ${ }^{35}$ with a 433A Applied
Biosystems (Foster City, CA) automatic synthesizer. Rink-amide MBHA resin $(0.78 \mathrm{mmol} / \mathrm{g}, 0.5 \mathrm{mmol}$ scale, $0.640 \mathrm{~g}$ ) was used. The elongation of $\mathrm{BN}(7-14)$ peptide (sequence: -Gln-Trp-Ala-Val-Gly-His-Leu-Met-Amide) was achieved by sequential addition of Fmoc-AA-OH with benzotriazol-1-yl-oxytripyrrolidinophosphonium hexafluorophosphate/1-hydroxy-1,2,3-benzotriazole/ N,N-diisopropylethylamine (PyBOP/HOBt/DIPEA) (1:1:2) as coupling reagents, in N,N-dimethylformamide (DMF) in pre-activation mode. All couplings were performed twice for 1 hour by using an excess of four equivalents of each amino acid derivative. Fmoc deprotection was obtained with a $30 \%$ solution of piperidine in DMF. When peptide synthesis was complete, the Fmoc N-terminal protecting group was removed and a residue of Fmoc-Ahoh-OH was condensed in a single coupling by using an excess of two equivalents. The resin was then washed, the terminal Fmoc protection removed and $1.064 \mathrm{~g}(2.0 \mathrm{mmol})$ of Dde-Lys(Fmoc)-OH were coupled to the resin by stirring the slurry suspension under standard conditions. The Fmoc-protecting group was removed by standard conditions, and the DTPA $(\mathrm{OtBu})_{4}-\mathrm{OH}$ tetraester chelating agent was linked, through its free carboxyl function, to the $\varepsilon-\mathrm{NH}_{2}$ of the lysine residue. This coupling step was performed using two equivalents of DTPA-tetraester and O-(7-azabenzotriazol-1-yl)-1,1,3,3-tetramethyluronium (HATU), and four equivalents of DIPEA in DMF. The coupling time for this step was increased to 2 hours. Removal of the Dde group was obtained by incubation with a DMF/hydrazine (98:2) mixture and the FmocNH-Peg27-COOH linker was coupled overnight by using HATU/DIPEA as activating agents and DMF as solvent. The N-terminal Fmoc protecting group was removed, and $1.244 \mathrm{~g}(2.0 \mathrm{mmol})$ of N,N-dioctadecylsuccinamic acid in $\mathrm{N}, \mathrm{N}$-dimethylformamide/dichloromethane (DMF/DCM) (1:1) mixture were condensed. Coupling was repeated twice for 1 hour. Peptide derivative was cleaved from the resin with TFA $(5 \mathrm{~mL})$ containing $2.5 \%(\mathrm{v} / \mathrm{v})$ water and $2.0 \%(\mathrm{v} / \mathrm{v})$ tri-isopropylsylane (TIS) as scavengers at room temperature for 2 hours. Free peptide was precipitated in cold ethyl ether and lyophilized from a $\mathrm{H}_{2} \mathrm{O} / \mathrm{CH}_{3} \mathrm{CN}$ (50/50) solution. Crude peptide was purified by reversed phase HPLC, and each fraction was characterized by LC-MS analysis.

$\left(\mathrm{C}_{18} \mathrm{H}_{37}\right)_{2} \mathrm{NCO}\left(\mathrm{CH}_{2}\right)_{2} \mathrm{CO}-\mathrm{Peg} 27-\mathrm{Lys}(\mathrm{DTPA})$-AhohGln-Trp-Ala-Val-Gly-His-Leu-Met-Amide; Mon Y-BN $\mathrm{Rt}=15.5 \mathrm{~min} ;(\mathrm{MW}=3669)[\mathrm{M}+4 \mathrm{H}]^{+} / 4=923 \mathrm{amu}$. 


\section{Synthesis of $\left(\mathrm{C}_{18} \mathrm{H}_{37}\right)_{2} \mathrm{CONHLys-(DTPA)CONH}$ $\left[\left(\mathrm{C}_{18}\right)_{2}\right.$ DTPA]}

The $\left(\mathrm{C}_{18} \mathrm{H}_{37}\right)_{2}$ CONHLys-(DTPA)CONH 2 [ $\left(\mathrm{C}_{18}\right)_{2}$ DTPA] monomer was synthesized according to the experimental procedure previously described. ${ }^{23}$

\section{Liposome preparation and Dox loading}

The liposomes were prepared by a modified reverse-phase evaporation technique. The lipid mixture composed of DSPC (7.90 mg) or DSPC/MonY-BN (7.66 mg DSPC, $1.10 \mathrm{mg}$ MonY-BN; 1:0.03 molar ratio) was dissolved in a chloroform/methanol $(2: 1 \mathrm{v} / \mathrm{v})$ mixture. The organic solution was added to a $50 \mathrm{~mL}$ round-bottom flask, and the solvent was removed under reduced pressure in a rotary evaporator under nitrogen atmosphere. The resulting lipid film was dissolved in $3 \mathrm{~mL}$ diethyl ether, and the solution was emulsified, by sonication for 30 minutes in a bath-type sonicator (Branson 3510, Danbury, CT), with $1 \mathrm{~mL}$ of citrate buffer at $\mathrm{pH} 4,0$ (150 mM of citric acid; $150 \mathrm{mM}$ of sodium citrate) or with $1 \mathrm{~mL}$ of ammonium sulfate buffer, $250 \mathrm{mM}$, at $\mathrm{pH} 5.5$, in the presence of glass beads. The resulting emulsion was then placed on a rotary evaporator (Laborota 4010 digital, Heidolph, Schwabach, Germany), and the organic solvent was removed under reduced pressure at $30^{\circ} \mathrm{C}$ in nitrogen atmosphere. When the viscous gel was obtained, the vacuum was broken and the gel was vortexed for about 1 minute. The dispersion was then placed in the rotary evaporator under vacuum for about 15 minutes. Citrate or ammonium buffer $(1 \mathrm{~mL})$ was subsequently added, and the suspension heated at $65^{\circ} \mathrm{C}$ for 30 minutes. The resulting liposome suspension was extruded at $65^{\circ} \mathrm{C}$, using a thermobarrel extruder system (Northern Lipids Inc, Vancouver, BC), passing the suspension repeatedly under nitrogen through a polycarbonate membrane (Nucleopore Track Membrane $25 \mathrm{~mm}$, Whatman, Brentford, UK) with $0.1 \mu \mathrm{m}$ pore size. The external buffer was removed by ultracentrifugation (Optima Max E, Beckman Coulter, Brea, CA; rotor TLA 120.2) at $80,000 \mathrm{rpm}$, at $4^{\circ} \mathrm{C}$ for 30 minutes, and the liposomes were resuspended with $1 \mathrm{~mL}$ of 4-(2-hydroxyethyl)-1-piperazineethanesulfonic acid (HEPES)-buffered saline (HBS) at pH 7.4 (20 mM of HEPES; $150 \mathrm{mM}$ of sodium chloride), giving a suspension with a total lipid concentration of $0.010 \mathrm{M}$. The actual phospholipid concentration of liposomes was determined according to Stewart's assay. ${ }^{36}$ Briefly, an aliquot of the liposome suspension was added to a two-phase system, consisting of an aqueous ammonium ferrothiocyanate solution $(0.1 \mathrm{~N})$ and chloroform. The concentration of DSPC was obtained by measuring the absorbance at $485 \mathrm{~nm}$ in the organic layer.
Dox was encapsulated into liposomes by remote loading. Briefly, the liposome suspension was combined with the Dox at a drug/lipid ratio of $0.2(\mathrm{w} / \mathrm{w})$, and then incubated at $65^{\circ} \mathrm{C}$ for 1 hour. The amount of unencapsuleted Dox was determined as follows: $1 \mathrm{~mL}$ of liposome dispersion was ultracentrifugated at $80,000 \mathrm{rpm}$ and $4^{\circ} \mathrm{C}$ for 30 minutes, the supernatant was carefully removed, and Dox concentration was determined with a UV-visible spectrophotometer at $480 \mathrm{~nm}$. The results have been expressed as encapsulation efficiency, calculated as $\left[\left(\mathrm{TS}_{\text {Dox }}-\mathrm{AS}_{\text {Dox }}\right) / \mathrm{TS}_{\text {Dox }}\right] \times 100$, where $\mathrm{TS}_{\mathrm{Dox}}$ is the theoretical Dox in the supernatant before encapsulation, and $\mathrm{AS}_{\mathrm{Dox}}$ is the actual Dox concentration in the supernatant. All liposome preparations were stored at $4^{\circ} \mathrm{C}$. Each formulation was prepared in triplicate.

Empty liposomes of DSPC/MonY-BN (3\%) and DSPC/ $(\mathrm{C} 18)_{2}$ DTPA $(0,1 \%)$ were also prepared with the same procedure for cell binding experiments.

\section{Liposomes characterization}

The mean diameter of the liposomes was determined at $20^{\circ} \mathrm{C}$ by photon correlation spectroscopy (PCS) (N5, Beckman Coulter. Each sample was diluted in deionizer/filtered water $(0.22 \mu \mathrm{m}$ pore size, polycarbonate filters, MF-Millipore, Microglass Heim, Italy) and analyzed with $\alpha$ detector at $\alpha 90^{\circ}$ angle. As a measure of the particle size distribution, the polydispersity index (PI) was used. For each batch, mean diameter and size distribution were the mean of three measurements. For each formulation, the mean diameter and PI were calculated as the mean of three different batches. The zeta-potential $(\zeta)$ of the liposome surface was measured in water by means of a Zetasizer Nano Z (Malvern, UK). Data of $\zeta$ were collected as the average of 20 measurements.

\section{Preparation of radiolabeled liposomes}

Radiolabeling of the DSPC/MonY-BN (3\%) and DSPC/ (C18) 2 DTPA (0.1\%) liposomes was performed at a final concentration of $2 \times 10^{-4} \mathrm{M}$. Trace amounts of ${ }^{111} \mathrm{InCl}_{3}$ $(1 \mu \mathrm{Ci}$ ) were added to $1 \mathrm{~mL}$ of the liposomes, and $1 \mathrm{~mL}$ of MilliQ water was added to reach a final volume of $2 \mathrm{~mL}$. The mixture was incubated for 120 minutes at room temperature. Confirmation of incorporation of the label into the liposomes was obtained by gel filtration on Sephadex G-50 pre-packed columns (Pharmacia Biotech, Piscataway, NJ).

\section{In-vitro studies}

PC-3 cells were seeded into 6-well plates wherein they remained overnight $\left(0.8-1.0 \times 10^{6}\right.$ cells per well). On the day of the experiment, the medium was removed, and the 
cells were washed twice with fresh medium (DMEM with $10 \%$ fetal bovine serum, 1\% L-glutamine) and incubated for 1 hour at $4^{\circ} \mathrm{C}$ and at $37^{\circ} \mathrm{C}$. Internalization experiments of the ${ }^{111}$ In-labeled liposomes were performed by adding $100 \mu \mathrm{L}^{111}$ In-labeled liposomes $(0.05 \mu \mathrm{Ci})$ to triplicate wells at a final concentration of $2 \times 10^{-4} \mathrm{M}$ and incubated for 1 hour at $37^{\circ} \mathrm{C} .{ }^{21}$ Afterwards, the binding buffer was removed, and the cells were washed twice with ice-cold phosphatebuffered saline (PBS) (pH 7.4). Cell bound radioactivity was subsequently recovered by trypsinization of the wells. Radioactivity in the bound and free fractions was determined with a Wizard gamma-counter (Wallac, Turku, Finland).

\section{Cytotoxicity assay}

Cytotoxicity of Dox-loaded liposomes, DSPC/MonY-BN/ Dox, and DSPC/Dox and of free Dox was determined using the colorimetric MTS (3-(4,5-dimethylthiazol-2yl)-5-(3-carboxymethoxyphenyl)-2-(4-sulfophenyl)$2 \mathrm{H}$-tetrazolium, inner salt) assay. Briefly, 8000 PC-3 cells/well were plated in 96-well plates and incubated overnight to allow cell attachment. The culture medium was removed, and cells were incubated with free Dox and liposomes containing 100 and $300 \mathrm{ng} / \mathrm{mL}$ Dox. Total lipid concentration in the cells was $500 \mathrm{ng}$ and $1500 \mathrm{ng}$ for the two Dox amounts, respectively. After 8 hours, the medium was removed and the cells were incubated for an additional 72 hours in fresh medium. Plates were then incubated with $20 \mu \mathrm{L}$ of MTS in $100 \mu \mathrm{L}$ of culture medium. Finally, $25 \mu \mathrm{L}$ of $10 \%$ SDS was added to all wells to stop the reaction, and mixed thoroughly. The absorbance was measured with a BioRad 680 microtiter plate reader (BioRad, BioRad, Corston, UK) at a wavelength of $490 \mathrm{~nm}$. Cells incubated with Dox-free liposomes were used as control. Viability was expressed as percentage of control (mean \pm standard error of the mean [SEM]) for each condition. The experiment was performed at least three times with triplicate wells. $\mathrm{IC}_{50}$ values for each treatment condition were calculated graphically.

\section{In-vivo experiments}

Animal experiments were carried out on 6-week-old female $\mathrm{BALB} / \mathrm{c}$ nude mice (Harlan Nossan, Italy). Mice bearing PC-3 xenografts of PC-3 cells were generated as previously described. ${ }^{13}$ Briefly, $100 \mu \mathrm{L}$ of the cell suspensions at a density of $2-3 \times 10^{7} \mathrm{~mL}^{-1}$ in PBS with $0.1 \%$ glucose and mixed with an equal volume of Matrige ${ }^{\mathrm{TM}}$ (BD Biosciences, Bedford, MA) were injected subcutaneously into the flank of mice (weighing 17-23 g). All procedures were performed inside a laminar air-flow cabinet using aseptic technique.
Tumor growth was measured every other day, starting 28 days following cell inoculation, using a digital caliper (Biological Instruments, Besozzo, VA, Italy). Approximately 5 weeks after cell implantation, when tumors reached an average volume of $200-250 \mathrm{~mm}^{3}$, mice were randomly distributed into three groups $(n=5)$ and intravenously (lateral tail vein) administered with $100 \mu \mathrm{L}$ of the following sterile formulations: saline buffer (control), DSPC/MonY-BN/ Dox (10 mg Dox/kg) and DSPC/Dox (10 mg Dox/kg). Drug dosage was adjusted with sterile PBS according to mean bodyweight for each group. Mice bodyweights were monitored twice a week following treatment. General animal health conditions were also evaluated to detect potential side effects, including food and water withdrawal, impaired movement, bodyweight loss, or behavioral changes. Procedures involving animals and their care were in conformity with institutional guidelines that comply with national and international laws and policies.

Tumor growth was then monitored for the following 22 days. The experiment was ended once control tumors reached a volume close to $1000 \mathrm{~mm}^{3}$, which was prior to deterioration of the animals' health condition. Tumor growth curves, obtained by plotting tumor volume $\left(\mathrm{mm}^{3}\right)$ versus treatment days, were determined for the different experimental groups. Percentage tumor growth inhibition (TGI) was determined as a measure of therapeutic activity for each treated group. All animal experiments complied with the Italian DL n 116 of 27 January 1992 and associate guidelines in the European Community Council Directive of 24 November 1986 (86/609/ECC).

\section{Results and discussion Design and synthesis}

The synthetic monomer, herein identified as MonY-BN for its Y shape (Figure 1), is a single molecule containing the following: (a) the hydrophobic moiety with two $\mathrm{C}_{18}$ alkyl chains that allows intercalation of the monomer in liposomal structures; (b) the $\mathrm{BN}(7-14)$ peptide that allows the interaction of the reconstituted aggregates with GRPRs overexpressed by cancer cells; and (c) the DTPA chelating agent able to give stable complexes with different metal ions, such as the ${ }^{111} \operatorname{In}(\mathrm{III})$ gamma-emitting isotope, used to monitor distribution through nuclear imaging techniques. Moreover, PEG and oxoethylene linkers have been introduced to space the bioactive peptide and the chelating agent from the two $\mathrm{C}_{18}$ hydrophobic chains. The PEG moiety also increases the overall hydrophilicity of the molecule, improves peptide exposure away from the liposome surface, and should provide lower 
clearance of the liposomes through the reticulo-endothelial system. ${ }^{37}$ The present authors previously studied supramolecular aggregates containing a MonY-CCK8 monomer or Mon Y-octreotide monomer intercalated in DOPC liposomes; the design of Mon Y-BN has been further optimized by using a long-chain PEG (MW = 1500 Dalton) spacer to distance the DTPA chelating agent from the hydrophobic moiety in order to favor the packing of the hydrocarbon chains in stable and well defined liposomes.

From a synthetic point of view, the Mon Y-BN monomer is based on a lysine scaffold. The ahoh oxyethylene spacer is linked on the lysine C-terminus and the $\mathrm{BN}(7-14)$ peptide; the DTPA chelating agent is bound, through an amide bond, on the lysine side-chain, while the N-alpha lysine function is functionalized with a long PEG containing 27 oxyethylene groups, acting as spacer, and the hydrophobic moiety consisting of two alkyl chains with 18 carbon atoms each.
The chemical synthesis was performed in solid-phase by using standard solid-phase-peptide-synthesis (SPPS) procedures based on Fmoc/tBu chemistry. ${ }^{35}$ Rink-amide resin was used to obtain a C-terminal amide peptide and the peptide built on the resin by sequential coupling and deprotection steps for the eight amino acid residues (see Figure 2). When the peptide synthesis was complete, the Fmoc N-terminal protecting group was removed and a residue of Fmoc-Ahoh-OH was added. Then, Dde-Lys(Fmoc)-OH was coupled, the Fmoc protecting group removed and the DTPA $(\mathrm{OtBu})_{4}-\mathrm{OH}$ tetraester chelating agent was linked, through its free carboxyl function, to the $\varepsilon-\mathrm{NH}_{2}$ of the lysine residue. After removal of the Dde group of the lysine residue, Fmoc-NH-Peg27$\mathrm{COOH}$ linker and N,N-dioctadecylsuccinamic acid were sequentially condensed. The peptide derivative was cleaved from the resin, and free peptide precipitated in cold ethyl ether and lyophilized. The crude compound was purified by
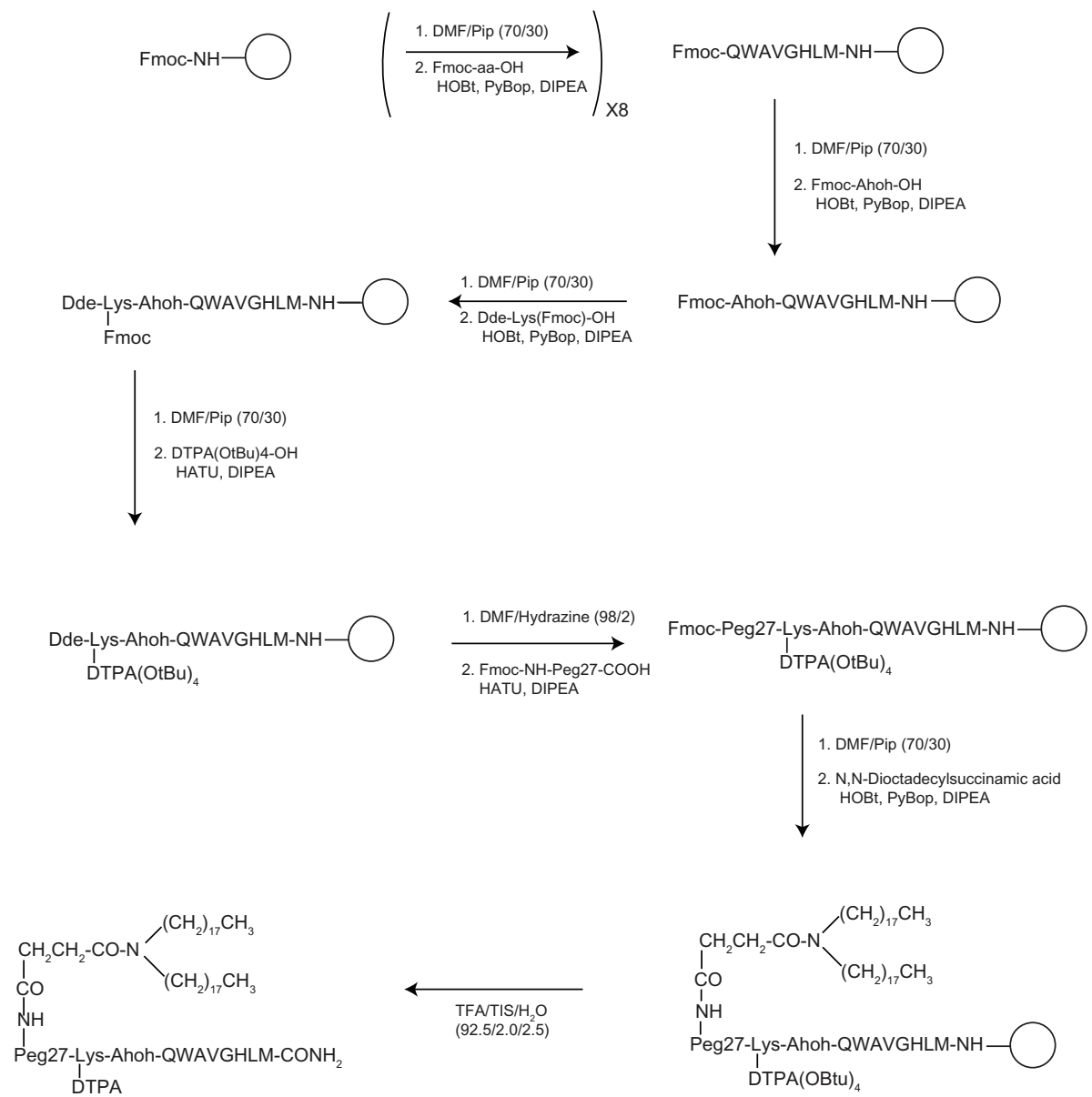

Figure 2 Synthetic procedure for obtaining MonY-BN by solid-phase methods.

Notes: The empty circle, o, represents the solid support (Rink amide resin). The first step of the scheme reports the Fmoc removal by using DMF/Pip (70/30) mixture and the amino acid (Fmoc-aa-OH) coupling under standard SPPS conditions. This step is repeated eightfold to obtain the BN(7-I4) sequence (reported according the single-letter amino acid code). Successively, solid-phase synthesis continues to bind on the peptide $\mathrm{N}$-terminus to the other organic components. In the last step, cleavage (TFA/TIS/ $\mathrm{H}_{2} \mathrm{O}$ ) from the resin is performed to give a fully unprotected carboxamide product.

Abbreviations: BN, bombesin; DMF, N,N-dimethylformamide; DTPA, diethylenetriaminepentaacetate; PEG, polyethylene glycol; SPPS, solid-phase-peptide-synthesis; TFA, trifluoroacetic acid; TIS, tri-isopropylsylane. 
reversed phase HPLC and characterized by LC-MS analysis and Maldi-Tof.

\section{Liposome preparation and characterization} Liposomes composed of DSPC (7.90 mg) or DSPC/ MonY-BN (7.66 mg DSPC, $1.10 \mathrm{mg}$ MonY-BN; 97/3 molar ratio) were prepared in HBS buffer solution $(1.0 \mathrm{~mL})$ at a final lipid concentration $0.010 \mathrm{M}$, and fully characterized. This formulation resulted from a preliminary phase of the study in which increasing amounts of Mon Y-BN were added into the bilayer with different lipid compositions. In this phase, in order to achieve a liposomal formulation with a mean diameter suitable for tumor targeting and with a homogeneous size distribution, a mean diameter lower than $200 \mathrm{~nm}$ and a PI lower than 0.2 , were considered pre-requisites to propose the formulation for following in-vitro and in-vivo experiments.

The zeta potential $(\zeta)$, mean diameter, and PI of the selected formulations, namely liposomes based on DSPC or DSPC/Mon Y-BN (97/3 molar ratio) are summarized in Table 1. The inclusion of $3 \%(\mathrm{~mol} / \mathrm{mol})$ MonY in the DSPC liposome composition led to reduction of the average size, and this effect could be attributed to the surfactant properties of MonY-BN. Moreover, a significant decrease of the zeta potential value (from about -6.7 to $-12.8 \mathrm{mV}$ ) was observed when using MonY-BN in the formulation. This result could be attributable to the four negative charges of the DTPA chelating agent and supports the presence of BN and/or DTPA on the outer vesicle membrane.

Subsequently, the drug-loading capability of DSPC/ MonY-BN (97/3 molar ratio) liposomes was investigated. Dox encapsulation into the liposomes was carried out by the remote-loading method at a drug/lipid $(\mathrm{w} / \mathrm{w})$ ratio of 0.2 . This value was selected according to the diameter of liposomes $(\mathrm{d}=150 \mathrm{~nm})$. In fact, the encapsulation efficiency of hydrophilic drugs such as Dox is related to the liposome size (eg, for Myocet ${ }^{\mathbb{}}, d=180 \mathrm{~nm}$ and drug/lipid is 0.27 , while for Doxil ${ }^{\circledR}, d=85 \mathrm{~nm}$ and drug/lipid decreases to 0.127 ).
The experimental conditions, namely the buffer used in the internal aqueous phase, the incubation time, as well as the incubation temperature, were optimized to achieve a drug-loading content $>90 \%$. The incubation time and temperature of liposomes in the presence of Dox represent two key parameters, which significantly affect drug loading of liposomes. As expected, drug-loading capability of liposomes was enhanced by increasing temperature (data not shown). Due to the presence of the peptide sequence in the final liposome formulation, an incubation temperature of $65^{\circ} \mathrm{C}$ was considered the upper limit. As it concerns incubation time, maximal drug loading was obtained at 1 hour while longer incubation time did not significantly change the encapsulation efficiency (data not shown). Moreover, liposome encapsulation efficiency was investigated under ammonium and citrate buffers. Buffer conditions strongly affect the drug-loading capability of liposomes: ${ }^{38}$ when ammonium buffer was used, an encapsulation efficiency $<60 \%$ was obtained, while a Dox encapsulation efficiency of approximately $95 \%$ was observed when using a citrate buffer in the aqueous phase of the liposomes (Table 1). As expected, liposome characteristics do not significantly change after Dox loading (Table 1).

\section{In-vitro studies}

Receptor-mediated cellular uptake at 1 hour of the targeted BN liposome formulation (DSPC/ $/{ }^{111} \mathrm{In}-\mathrm{Mon} \mathrm{Y}-\mathrm{BN}$ ) in PC-3 cell lines at $4^{\circ} \mathrm{C}$ and $37^{\circ} \mathrm{C}$, was estimated with gamma counting experiments. To confirm the selective binding capability of the targeted liposomes, cellular uptake of radiolabeled pure DSPC liposomes was also performed for comparison. To prepare the radiolabeled control liposomes, a low amount $(0.1 \%)$ of the amphiphilic monomer $\left(\mathrm{C}_{18}\right)_{2}$ DTPA was introduced in DSPC liposomes. A small amount of this monomer does not significantly alter the size and shape of the liposomes (data not shown). A complete radiolabeling of the liposomes was performed at $2 \times 10^{-4} \mathrm{M}$ concentration by adding trace amounts of ${ }^{111} \mathrm{InCl}_{3}$. Incorporation of the radioactive label into the aggregates was confirmed by gel filtration.

Table I Liposome characteristics

\begin{tabular}{lllllll}
\hline Formulations & $\begin{array}{l}\text { Composition } \\
\text { of the lipid bilayer }\end{array}$ & $\begin{array}{l}\text { Composition of } \\
\text { the aqueous phase }\end{array}$ & $\begin{array}{l}\text { Liposome diameter } \\
(\mathbf{n m}) \pm \text { SD }\end{array}$ & PI \pm SD & $\begin{array}{c}\zeta \text { mV } \pm \text { SD } \\
\text { Dox encapsulation } \\
\text { efficiency (\%) }\end{array}$ \\
\hline DSPC liposomes & DSPC & PBS & $161.4 \pm 20.1$ & $0.09 \pm 0.01$ & $-6.7 \pm 1.8$ & - \\
MonY liposomes & DSPC/MonY-BN & PBS & $145.5 \pm 31.5$ & $0.20 \pm 0.05$ & $-12.8 \pm 1.5$ & - \\
$\begin{array}{l}\text { Dox-MonY } \\
\text { liposomes }\end{array}$ & DSPC/MonY-BN & Ammonium buffer & $165.2 \pm 42.0$ & $0.24 \pm 0.07$ & $-12.8 \pm 3.6$ & $58.0 \pm 19.0$ \\
$\begin{array}{l}\text { Dox-MonY } \\
\text { liposomes }\end{array}$ & DSPC/MonY-BN & Citrate buffer & $150.8 \pm 28.3$ & $0.13 \pm 0.08$ & $-12.0 \pm 1.0$ & $95.0 \pm 2.7$ \\
\hline
\end{tabular}

Abbreviations: Dox, doxorubicin; DSPC, I,2-distearoyl-sn-glycero-3-phosphocholine; PBS, phosphate-buffered saline; PI, polydispersity index; SD, standard deviation. 
Specific preferential binding to PC-3 cells of mixed liposomes containing the $\mathrm{BN}(7-14)$ peptide sequence was observed $\left(2.7 \pm 0.3\right.$, at $\left.37^{\circ} \mathrm{C}\right)$, compared with the pure DSPC liposomes $\left(1.4 \pm 0.2\right.$ at $37^{\circ} \mathrm{C}$ ) (see Figure 3), indicating preserved interaction of the $\mathrm{BN}(7-14)$ bioactive peptide on the external surface of the liposomes with the GRPR on the surface of the cells.

\section{Cytotoxicity assays}

The cytotoxic effect of DSPC/MonY-BN/Dox on PC-3 prostate cancer cells was also assessed. PC-3 cells were exposed to liposome formulations $(100 \mu \mathrm{L})$ containing 500 or $1500 \mathrm{ng}$ of lipids and 100 or $300 \mathrm{ng}$ of Dox, respectively, for 8 hours, and the cell viability was measured by MTS assays (Figure 4). Incubation of cells with DSPC/MonY-BN/ Dox showed significantly lower cell survival compared with DSPC/Dox-treated cells in the presence of $100 \mathrm{ng} / \mathrm{mL}$ and $300 \mathrm{ng} / \mathrm{mL}$ drug amounts. On the other hand, liposomal Dox below $100 \mathrm{ng} / \mathrm{mL}$ concentration showed no significant differences on cell survival. In experiments performed with free Dox, $50 \%$ cell killing was observed with $85 \mathrm{ng} / \mathrm{mL}$ of drug (data not shown). This result suggests a lower toxicity of the liposomal cytotoxic drug compared to the free-drug. This result is expected as when cells are exposed to free Dox and liposomal Dox for the same amount of time, free Dox is taken up much more rapidly.

The increased potency of DSPC/MonY-BN/Dox with respect to DSPC/Dox is fully attributed to Dox because control experiments with empty liposomes had no significant effect on cell viability.

\section{In-vivo studies}

Preliminary studies on the therapeutic efficacy of DSPC/ MonY-BN/Dox targeted liposomes compared with pure

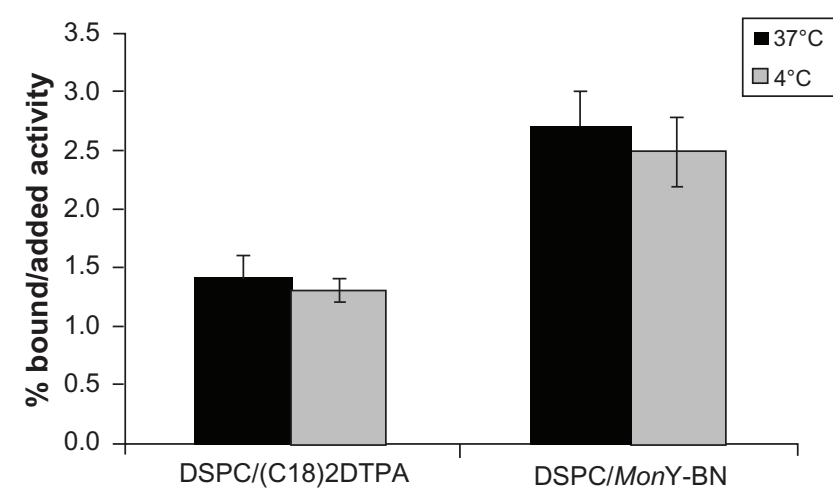

Figure 3 Binding assays of DSPC/MonY-BN and DSPC/(C 18$)_{2}$ DTPA $^{\prime \prime \prime}$ In-radiolabeled liposomes on PC-3 cell line overexpressing the GRP at $37^{\circ} \mathrm{C}$ and $4^{\circ} \mathrm{C}$ at I hour. Abbreviations: BN, bombesin; DSPC, I,2-distearoyl-sn-glycero-3-phosphocholine; DTPA, diethylenetriaminepentaacetate; GRP, gastrin-releasing peptide.

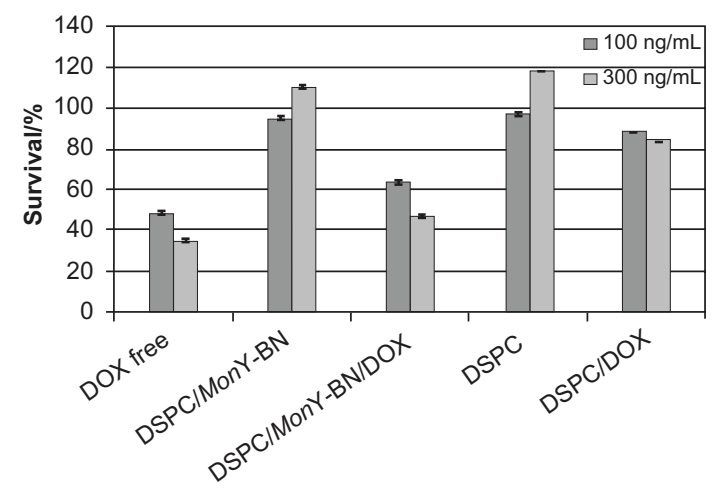

Figure 4 Cytotoxicity of liposomal Dox against human prostatic cancer cells. Notes: PC-3 cells (8000 cells/well) were incubated with DSPC/MonY-BN/Dox, DSPC/Dox, and free Dox at $37^{\circ} \mathrm{C}$ (liposome formulations containing 500 or $1500 \mathrm{ng}$ of lipids and 100 or $300 \mathrm{ng}$ of Dox, respectively). Control experiments were performed using free Dox, and empty liposomes of DSPC/MonY or DSPC at the same experimental conditions. After 8 hours, the medium was removed, and after an additional 72 hours an MTS assay was performed. Data are expressed as percentage of control. Each value is the mean \pm SEM of three experiments performed in triplicate.

Abbreviations: BN, bombesin; Dox, doxorubicin; DSPC, 1,2-distearoyl-sn-glycero3-phosphocholine; MTS, 3-(4,5-dimethylthiazol-2-yl)-5-(3-carboxymethoxyphenyl)2-(4-sulfophenyl)-2H-tetrazolium; SEM, standard error of the mean.

DSPC/Dox liposomes were conducted in PC-3 xenograftbearing mice, by treating mice with intravenous injections of $100 \mu \mathrm{L}$ of liposome suspensions $\left(1.0 \times 10^{-2} \mathrm{M}\right.$ lipid concentration, at a dose of $10 \mathrm{mg}$ of Dox $/ \mathrm{kg}$ ). Control experiments on mice treated with saline buffer were also performed. $1 \times 10^{6}$ cells per animal were injected in the flank of 6-week-old BALB/c nude mice in a solution containing 1:1 Matrigel ${ }^{\mathrm{TM}}$.

Matrigel $^{\mathrm{TM}}$ is an extract of basement membrane components, which primarily consists of laminin, collagen IV, and heparin sulfate proteoglycan. ${ }^{39}$ Its co-injection with cancer cells into subcutaneous tissues aims to stimulate growth of biologically indolent tumors..$^{40}$ Once the tumor model was established, another important challenge was to determine the most appropriate treatment experimental conditions with regard to tumor volume at the beginning of treatment, treatment groups, dose escalation, and end point conditions, such as duration of the observation period after treatment. After evaluating the influence of the referred experimental parameters, the treatment protocol was established: a single dose was administered intravenously at an advanced phase of tumor development (200-250 $\left.\mathrm{mm}^{3}\right)$. The experiment was stopped when untreated tumors reached a size close to $1000 \mathrm{~mm}^{3}$. Bodyweights of all mice were recorded periodically to assess nonspecific toxicity. There were no signs of clinical toxicity, and all animals gained weight and survived the entire experimental period (data not shown). Therapeutic efficacy was assessed by measuring tumor volume over 


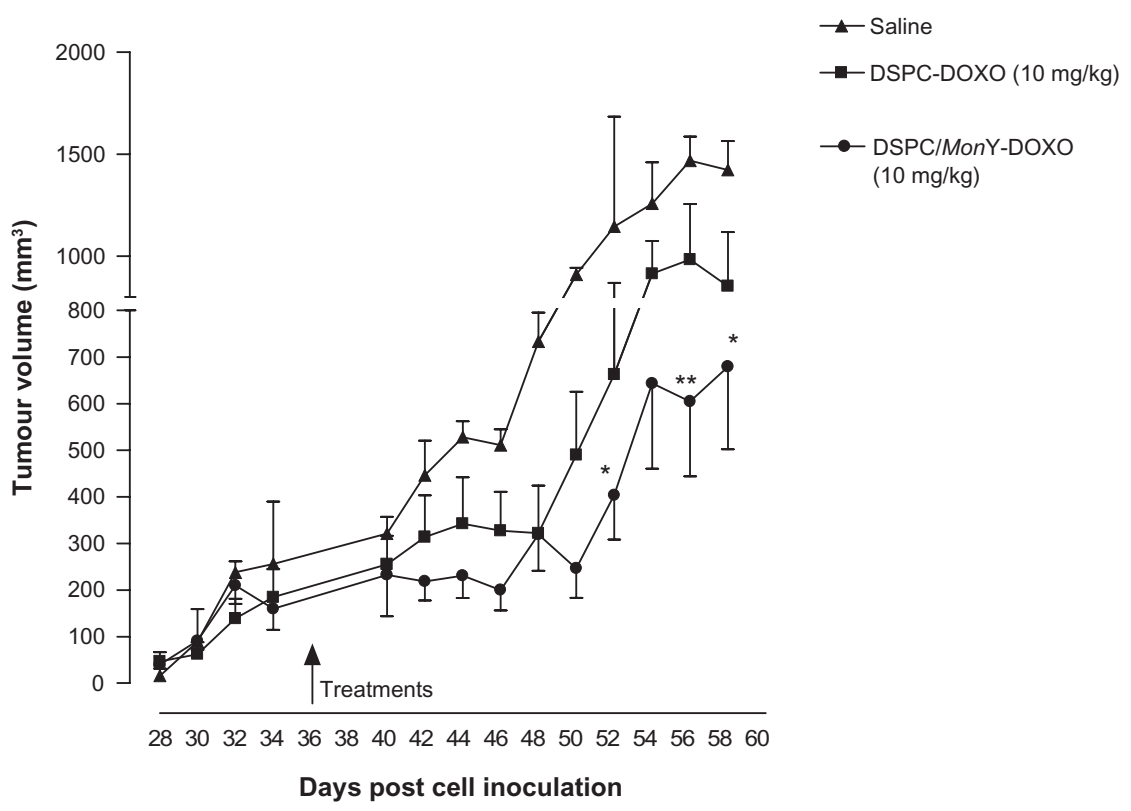

Figure 5 Comparative efficacy study in BALB/c nude mice bearing xenografts (PC-3) on tumor growth.

Notes: Treatment started approximately 5 weeks after cell implantation. Mice $(n=5)$ were administered intravenously with injection of I00 $\mu \mathrm{L}$ of liposome suspensions of DSPC/MonY-BN/Dox, or DSPC/Dox (I.0 × 10-2 M lipid concentration, at a dose of $10 \mathrm{mg}$ of Dox $/ \mathrm{kg}$ ) or $100 \mu \mathrm{L}$ of HBS buffer (control). Therapeutic efficacy was assessed by measuring tumor volume (mean $\pm \mathrm{SD}$ ) over time. Results were analyzed using two-way analysis of variance, followed by Bonferroni's test. * denotes $P<0.05$ and $* *$ denotes $P<0.0$ I versus saline. DSPC/MonY-BN/Dox and DSPC/Dox produce, with respect to the saline solution, a TGI of $60 \%$ and $36 \%$, respectively.

Abbreviations: BN, bombesin; Dox, doxorubicin; DSPC, I,2-distearoyl-sn-glycero-3-phosphocholine; HEPES, 4-(2-hydroxyethyl)-I-piperazineethanesulfonic acid; HBS, HEPES buffered saline; SD, standard deviation; TGI, tumor growth inhibition.

time. Data were expressed as mean $\pm \operatorname{SEM}(\mathrm{n}=5)$ and analyzed using two-way analysis of variance followed by Bonferroni's test; a value of $P<0.05$ was considered statistically significant.

Treatment with liposomal formulations was effective in slowing tumor progression over an extended period of time (see Figure 5). In particular, treatment with DSPC/ Mon Y-BN/Dox at $10 \mathrm{mg} / \mathrm{kg}$ Dox dose produced a TGI of $60 \%$, compared with the treatment with saline buffer. Furthermore, a decrease in tumor growth was also observed (TGI $=36 \%$ ), compared with mice treated with nonspecific liposomes of DSPC/Dox at the same Dox dose.

\section{Conclusion}

A new drug-delivery system, DSPC/MonY-BN (97/3 molar ratio), based on liposomes functionalized with the bioactive sequence of the BN peptide and with a chelating agent, has been developed by incorporating a new amphiphilic synthetic monomer, MonY-BN, in a liposome-forming commercial phospholipid, DSPC. The liposomes structure, the drugloading ability, the selective cellular binding and cytotoxicity, and the in-vivo therapeutic efficacy were assessed. The simultaneous presence of the bioactive $\mathrm{BN}$ peptides, provide targeting ability for the liposomes, and of the chelating agents, which allow radiolabeling for diagnostic nuclear medicine applications, makes these liposomes potential target-selective theranostic agents. ${ }^{41}$

All the structural and loading properties, similar to other drug-delivery systems already in clinical use (eg, Myocet ${ }^{\circledR}$ and Caelyx ${ }^{\circledR} /$ Doxil $^{\circledR}$ ), and the observed in-vitro and in-vivo behaviors point toward a potential clinical use of the new liposomes for Dox delivery in cancer therapy. Areas of clinical interest are applications in patients with ovarian, breast, and prostate cancer, where a number of studies have documented the overexpression of GRPRs. ${ }^{28-30}$ The high incidence of these diseases and the lack of adequate treatment strategies in advanced stages warrant development of more effective strategies.

\section{Acknowledgments}

This work was supported by grants from the Italian Minister of Research (MIUR): Grant FIRB RBRN07BMCT and Grant PRIN E61J11000300001.

\section{Disclosures}

A Accardo, D Tesauro, and G Morelli, have participated in a spin-off company (Invectors, srl) devoted to the clinical development of the described compounds for cancer therapy. The other authors report no conflicts of interest in this work. 


\section{References}

1. Chabner BA, Allegra CJ, Curt GA, Calabresi P. Antineoplastic agents. Hardman JG, Limbird LE, editors. Goodman and Gillman's The Pharmacological Basis of Therapeutics, 9th ed. New York: McGrawHill; 1996:1265.

2. Hortobagyi GN. Anthracyclines in the treatment of cancer: an overview. Drugs. 1997;54 Suppl 4:1-7.

3. Gabizon A, Martin F. Polyethylene glycol-coated (pegylated) liposomal doxorubicin: rationale for use in solid tumours. Drugs. 1997;54 Suppl 4: $15-21$.

4. Gabizon A. Pharmacokinetics of PEGylated liposomal doxorubicin. Clin Pharmacokinet. 2003;42:419-436.

5. Abraham SA, Waterhouse DN, Lawrence D, et al. The liposomal formulation of doxorubicin. Methods Enzymol. 2005;391:71-97.

6. Tardi PG, Boman NL, Cullis PR. Liposomal doxorubicin. J Drug Target. 1996;4:129-140.

7. Brown JM, Giaccia AJ. The unique physiology of solid tumours: opportunities (and problems) for cancer therapy. Cancer Res. 1998;58:408-1416.

8. Gabizon A, Catane R, Uziely B, et al. Prolonged circulation time and enhanced accumulation in malignant exudates of doxorubicin encapsulated in poly-ethylene-glycol coated liposomes. Cancer Res. 1994;54:987-992.

9. Gaber MH, Wu NZ, Hong K, Huang SK, Dewhirst MW, Papahadjopoulos D. Thermosensitive liposomes: extravasation and release of contents in tumor microvascular networks. Int J Radiat Oncol Biol Phys. 1996;36:1177-1187.

10. Matsumura Y, Maeda H. A new concept for macromolecular therapeutics in cancer chemotherapy: mechanism of tumoritropic accumulation of proteins and the antitumor agent smancs. Cancer Res. 1986;46:6387-6392.

11. Marcucci F, Lefoulon F. Active targeting with particulate drug carriers in tumor therapy: fundamentals and recent progress. Drug Discov Today. 2004;9(5):219-228.

12. Torchilin VP. Antibody-modified liposomes for cancer chemotherapy. Expert Opin Drug Deliv. 2008;5(9):1003-1025.

13. Sofou S, Sgouros G. Antibody-targeted liposomes in cancer therapy and imaging. Expert Opin Drug Deliv. 2008;5(2):189-204.

14. Wu H-C, Chang D-K. Peptide-mediated liposomal drug delivery system targeting tumor blood vessels in anticancer therapy. $J$ Oncol. 2010;2010:1-8.

15. Reubi JC, Waser B, Schaer JC, Laissue JA. Somatostatin receptor sst1sst5 expression in normal and neoplastic human tissues using receptor autoradiography with subtype-selective ligands. Eur J Nucl Med. 2001;28(7):836-846.

16. Virgolini I, Raderer M, Kurtaran A, et al. Vasoactive intestinal peptidereceptor imaging for the localization of intestinal adenocarcinomas and endocrine tumors. N Engl J Med. 1994;331:1116-1121.

17. Behr TM, Jenner N, Radetzky S, et al. Targeting of cholecystokinin-B/ gastrin receptors in vivo: preclinical and initial clinical evaluation of the diagnostic and therapeutic potential of radiolabelled gastrin. Eur $J$ Nucl Med. 1998;25(4):424-430.

18. Breeman WA, de Jong M, Erion JL, et al. Preclinical comparison of 111 In-labeled DTPA- or DOTA-bombesin analogs for receptortargeted scintigraphy and radionuclide therapy. $J \mathrm{Nucl} \mathrm{Med.}$ 2002;43:1650-1656.

19. Behr TM, Gotthardt M, Barth A, Behe M. Imaging tumors with peptidebased radioligands. Q J Nucl Med. 2001;45(2):189-200.

20. Accardo A, Morisco A, Tesauro D, Pedone C, Morelli G. Naposomes: a new class of peptide derivatized target selective multimodal nanoparticles for imaging and therapeutic applications. Ther Deliv. 2011;2(2):235-257.

21. Accardo A, Tesauro D, Aloj L, et al. Peptide containing aggregates as selective nanocarriers for therapeutics. Chem Med Chem. 2008; 3:594-602.
22. Morisco A, Accardo A, Tesauro D, Palumbo R, Benedetti E, Morelli G. Peptide-labeled supramolecular aggregates as selective doxorubicin carriers for delivery to tumor cells. Biopolymers. 2011;96(1):88-96.

23. Accardo A, Morisco A, Gianolio E, et al. Nanoparticles containing octreotide peptides and gadolinium complexes for MRI applications. J Pept Sci. 2011;17(2):154-162.

24. Vaccaro M, Mangiapia G, Paduano L, et al. Structural and relaxometric characterization of peptide aggregates containing gadolinium complexes as potential selective contrast agents in MRI. Chem Phys Chem. 2007:8:2526-2538.

25. Ding N, Lu Y, Lee RJ, et al. Folate receptor-targeted fluorescent paramagnetic bimodal liposomes for tumor imaging. Int J Nanomedicine. 2011;6:2513-2520.

26. Lammers T, Aime S, Hennink WE, Storm G, Kiessling F. Theranostic nanomedicines. Acc Chem Res. 2011;44(10):1029-1038.

27. Accardo A, Mansi R, Morisco A, et al. Peptide modified nanocarriers for selective targeting of bombesin receptors. Mol Biosyst. 2010; 6:878-887.

28. Markwalder R, Reubi JC. Gastrin-releasing peptide receptors in the human prostate: relation to neoplastic transformation. Cancer Res. 1999;59:1152-1159.

29. Gugger M, Reubi JC. GRP receptors in non-neoplastic and neoplastic human breast. Am J Pathol. 1999;155:2067-2076.

30. Fleischmann A, Waser B, Reubi JC. Overexpression of gastrin-releasing peptide receptors in tumor-associated blood vessels of human ovarian neoplasms. Cell Oncol. 2007;29:421-433.

31. Smith CJ, Volkert WA, Hoffman TJ. Radiolabeled peptide conjugates for targeting of the bombesin receptor superfamily subtypes. Nucl Med Biol. 2005;32:733-740.

32. Rogers BE, Bigott HM, McCarthy DW, et al. MicroPET Imaging of a gastrin-releasing peptide receptor-positive tumor in a mouse model of human prostate cancer using a $64 \mathrm{Cu}$-labeled bombesin analogue. Bioconjugate Chem. 2003;14(4):756-763.

33. Parry JJ, Kelly TS, Andrews R, Rogers BE. In vitro and in vivo evaluation of 64Cu-labeled DOTA-linker-bombesin(7-14) analogues containing different amino acid linker moieties. Bioconjugate Chem. 2007;18(4):1110-1117.

34. Schmitt L, Dietrich C. Synthesis and characterization of chelator-lipids for reversible immobilization of engineered proteins at self-assembled lipid interfaces. J Am Chem Soc. 1994;116(19):8485-8491.

35. Chang WC, White PD. Fmoc Solid Phase Peptide Synthesis. Oxford, UK: Oxford Univ Press; 2000.

36. Stewart JCM. Colorimetric determination of phospholipids with ammonium ferrothiocyanate. Anal Biochem. 1980;104:10-14.

37. Allen TM, Hansen C, Martin F, Redemann C, Yau-Young A. Liposomes containing synthetic lipid derivatives of poly(ethylene glycol) show prolonged circulation half-lives in vivo. Biochim Biophys Acta Biomembranes. 1991;1066(1):29-36.

38. Fritze A, Hens F, Kimpfler A, Schubert R, Peschka-Süss R. Remote loading of doxorubicin into liposomes driven by a transmembrane phosphate gradient. Biochimica et Biophysica Acta. 2006;1758(10):1633-1640.

39. An Z, Wang X, Geller J, Moossa AR, Hoffman RM. Surgical orthotopic implantation allows high lung and lymph node metastatic expression of human prostate carcinoma cell line PC-3 in nude mice. Prostate. 1998;34(3):169-174.

40. Fridman R, Kibbey MC, Royce LS, et al. Enhanced tumor growth of both primary and established human and murine tumor cells in athymic mice after coinjection with Matrigel. J Natl Cancer Inst. 1991;83(11):769-774.

41. Xie J, Lee S, Chen X. Nanoparticle-based theranostic agents. Adv Drug Deliv Rev. 2010;62:1064-1079. 
International Journal of Nanomedicine

Dovepress

\section{Publish your work in this journal}

The International Journal of Nanomedicine is an international, peerreviewed journal focusing on the application of nanotechnology in diagnostics, therapeutics, and drug delivery systems throughou the biomedical field. This journal is indexed on PubMed Central, MedLine, CAS, SciSearch ${ }^{\circledR}$, Current Contents ${ }^{\circledR} /$ Clinical Medicine,
Journal Citation Reports/Science Edition, EMBase, Scopus and the Elsevier Bibliographic databases. The manuscript management system is completely online and includes a very quick and fair peer-review system, which is all easy to use. Visit http://www.dovepress.com/ testimonials.php to read real quotes from published authors.

Submit your manuscript here: http://www.dovepress.com/international-journal-of-nanomedicine-journal 